\title{
ANALISIS PENGENDALIAN KUALITAS PRODUK ROTI DENGAN MENGGUNAKAN PETA P DAN 7 TOOLS OF QUALITY
}

\author{
Gunawan Mohammad \\ Program Studi Teknik Industri, Fakultas Sains \& Teknologi, UNISNU Jepara \\ gunawan@unisnu.ac.id
}

\begin{abstract}
PT Candrabuaya Surya Semesta is a company that produces catering and bread, one of which is located in the Jepara City. Increasing competition in the catering and bread business requires companies to be able to maintain and improve their quality to retain customers. The purpose of this study is to determine the level of product quality and to determine the factors that caused the quality of a product from the company. The sweet wet bread product is a superior product that more customer interested, so in this study (research) used analysis of product quality control with $P$ maps and seven tools of quality. There are two main defects in the production process of sweet wet bread, namely the dough does not expand and baking is not perfect. Of the two defects, the defect of the dough does not develop into a priority proposal for improvements that must be done by the company. The common factors that cause disability are method factors in the production process, equipment used, human reliability factors, and materials / raw materials used.
\end{abstract}

Keywords: quality, control, analysis, Map P, seven

\begin{abstract}
Abstrak
PT Candrabuaya Surya Semesta merupakan perusahaan dalam bidang catering dan roti yang salah satu cabangnya terdapat di kota Jepara. Semakin banyaknya persaingan dalam usaha catering dan roti menuntut perusahaan untuk dapat menjaga dan meningkatkan kualitasnya untuk mempertahankan pelanggan. Tujuan dari penelitian ini adalah untuk mengetahui tingkat kualitas produk dan menentukan faktor-faktor yang menjadi penyebab dari kualitas dari sebuah produk dari perusahaan. Produk roti basah manis menjadi produk unggulan yang diminati pelanggan, sehingga dalam penelitian ini dilakukan analisis pengendalian kualitas produk dengan menggunakan peta $P$ dan seven tools. Terdapat dua cacat utama dalam proses produksi roti basah manis yaitu adonan tidak mengembang dan pembakaran tidak sempurna. Dari kedua cacat tersebut, cacat adonan tidak mengembang menjadi usulan prioritas dalam perbaikan yang harus dilakukan oleh perusahaan. Faktor umum yang menjadi penyebab kecacatan tersebut adalah faktor metode dalam proses produksi, peralatan yang digunakan, faktor kehandalan manusia, dan material/bahan baku yang digunakan.
\end{abstract}

Kata Kunci : analisis, pengendalian, kualitas, peta $P$, seven

\section{PENDAHULUAN}

Perkembangan industri catering dan perusahaan roti akhir-akhir ini mengalami peningkatan cukup pesat. Hal ini dapat dilihat dengan semakin banyaknya produsen roti baik skala UMKM maupun perusahaan dalam skala besar. Bisnis catering menjadi peluang bisnis yang menguntungkan dengan pertumbuhan potensi pasar yang sangat besar. Menurut Maulana Wahyu Jumantara pertumbuhan ratarata bisnis roti dan kue 2010-2014 meningkat $14 \%$, sedangkan proyeksi proyeksi pertumbuhan 2014-2020 pertumbuhan ditargetkan 10\%. (Kontan, 2017) Jepara merupakan salah satu kota dengan tradisi cukup banyak kegiatankegiatan yang mengundang banyak saudara, kerabat, bahkan warga sekitar. Dari upacara adat desa, perayaan-perayaan yang bersifat rutinan baik dari tingkat desa, maupun tingkat kabupaten. Seperti : Peringatan Hari Jadi Jepara, Hari Kartini, Karnaval 17 Agustus, ramadhan. Dan juga perayaan-perayaan pesta ulang tahun, pernikahan, dan lain sebagainya. 
Fenomena kegiatan tersebut tidak lepas dari kebutuhan catering dan roti.

Semakin banyaknya pertumbuhan produsen-produsen baru dalam bisnis catering dan roti tidak dapat lagi konsumen ketergantungan terhadap salah satu produsen saja. Perkembangan tersebut menyebabkan persaingan menjadi terfokus pada kualitas. Kualitas suatu produk adalah salah satu aspek penting dalam sebuah industri. Konsumen pada era modern ini sangatlah cerdas dalam memilih produk yang dibutuhkan, dimana para konsumen ini tidak hanya melihat dari aspek harga saja, tetapi juga kualitasnya.

PT. Candrabuana Surya Semesta adalah salah satu perusahaan pada bidang industri makanan roti dan kue. Perusahaan ini memiliki cabang pabrik dan outlet yang berada hampir diseluruh wilayah Indonesia, salah satunya di Jepara merupakan perusahaan yang memproduksi beberapa jenis roti dan cake yang bervariasi. Produk-produk yang diproduksi perusahaan tersebut tak lepas adanya kualitas yang selalu menjadi kepentingan tersendiri bagi perusahaan maupun konsumen. Setelah melakukan pengamatan selama beberapa hari di perusahaan tersebut ditemukan beberapa masalah yang terjadi yang menyangkut standar kualitas produk roti dan cake diantaranya yaitu terjadinya kecacatan pada produk roti yang mengakibatkan kerugian dan mengurangi kualitas dari produk tersebut. Hal itu melatarbelakangi adanya penelitian standar mutu/kualitas untuk mengatasi permasalahan yang ada melalui pendekatan Statistical Quality Control ( SQC ).

Proses pengendalian kualitas dapat didentifikasi dengan menggunakan beberapa peta kendali dan analisis berdasarkan seven tools of quality. Sehingga dengan adanya penelitian ini, diharapkan dapat menjadi acuan perusahaan dalam melakukan perbaikan dan prioritas perbaikan yang akan dilakukan untuk menjaga dan meningkatkan kualitas.

\section{TINJAUAN PUSTAKA}

1. Kualitas

Beberapa pengertian kualitas menurut para ahli, diataranya :

1. kualitas adalah segala sesuatu yang berkaitan dengan produk baik berupa barang maupun jasa, manusia, proses, dan lingkungan sekitar yang memenuhi bahkan melebihi harapan (Tjiptono \& Diana, 2003)

2. kualitas adalah faktor yang menjadikan suatu produk bernilai sesuai dengan standar produksi yang telah ditentukan dari suatu produk (Handoko, 1999)

3. kualitas adalah keseluruhan bentuk dan karakteristik dari suatu produk, baik berupa barang atau jasa yang menunjukkan kemampuan untuk memenuhi kebutuhan konsumen baik secara langsung maupun tak langsung (Render, 2001)

Dari beberapa definisi diatas, rangkuman definisi kualitas adalah kesesuaian antara produk yang dihasilkan dengan harapan dan kebutuhan dari konsumen.

\section{Pengertian Pengendalian Kualitas}

Pengendalian kualitas menurut Gasperz (2005) adalah upaya organisasi menerapkan manajemen kualitas terhadap produk secara konsisten untuk memenuhi kebutuhan dan harapan pelanggan. Pengendalian kualitas adalah instrumen utama bagi manajemen produksi untuk menjaga, mempertahankan, dan memperbaiki kualitas produk supaya sesuai dengan standar yang telah ditentukan.

3. Tujuan pengendalian kualitas

Tujuan pengendalian kualiatas menurut Suyadi Prawirosentono (2009) adalah sebagai berikut :

1. Mengawasi pelaksanaan proses produksi agar sesuai dengan rencana

2. Mengawasi bahan baku sejak diterima, disimpan, dan dikeluarkan dari gudang bahan baku.

4. Alat dari Pengukuran Kualitas (Total Quality Manajemen)

Beberapa alat pengukuran kualitas yang sering disebut sebagai seven tools of quality, adalah sebagai berikut (Jay Heizer \& Barry Render, 2015) : 
1. Lembar periksa / checklist sheet

Lembar periksa adalah sebuah formulir yang dirancang untuk mencatat data.

2. Diagram pencar / scatter diagram

Diagram pencar menunjukkan hubungan antara dua penilaian. Jika dua hal saling berkaitan, titik data akan membentuk kelompok yang sangat dekat. Jika menghasilkan pola yang acak, hal-hal tersebut tidak berkaitan

3. Diagram sebab-akibat / cause and effect diagram

Diagram sebab-akibat juga dikenal dengan diagram ishikawa atau fishbone chart. Fishbone-chart adalah sebuah alat yang mengidentifikasikan elemen proses (penyebab) yang mungkin mempengaruhi hasil.

4. Diagram pareto

Diagram pareto adalah salah satu cara dalam mengurutkan prioritas kesalahan atau cacat untuk menjadi acuan fokus dalam usaha penyelesaian masalah. Diagram pareto menghasilakn indikasi masalah yang memberikan hasil yang terbesar.

5. Diagaram Histogram

Histogram menunjukkan rentang nilai dari pengukuran dan frekuensi dimana setiap nilai terjadi. Histogram merupakan gambaran distribusi yang menunjukkan frekuensi dari kemunculan variabel.

6. Diagram alur

Diagram alur adalah diagram yang menampilkan sebuah proses atau sistem dengan menggunakan kotak dan bulat sebagai simbol dan garis yang saling berhubungan.

7. Grafik pengendalian (control chart)

Grafik pengendalian adalah presentase grafik dari proses data dari waktu ke waktu yang menunjukkan batas kendali atas dan batas kendali bawah untuk proses yang akan dikendalikan.

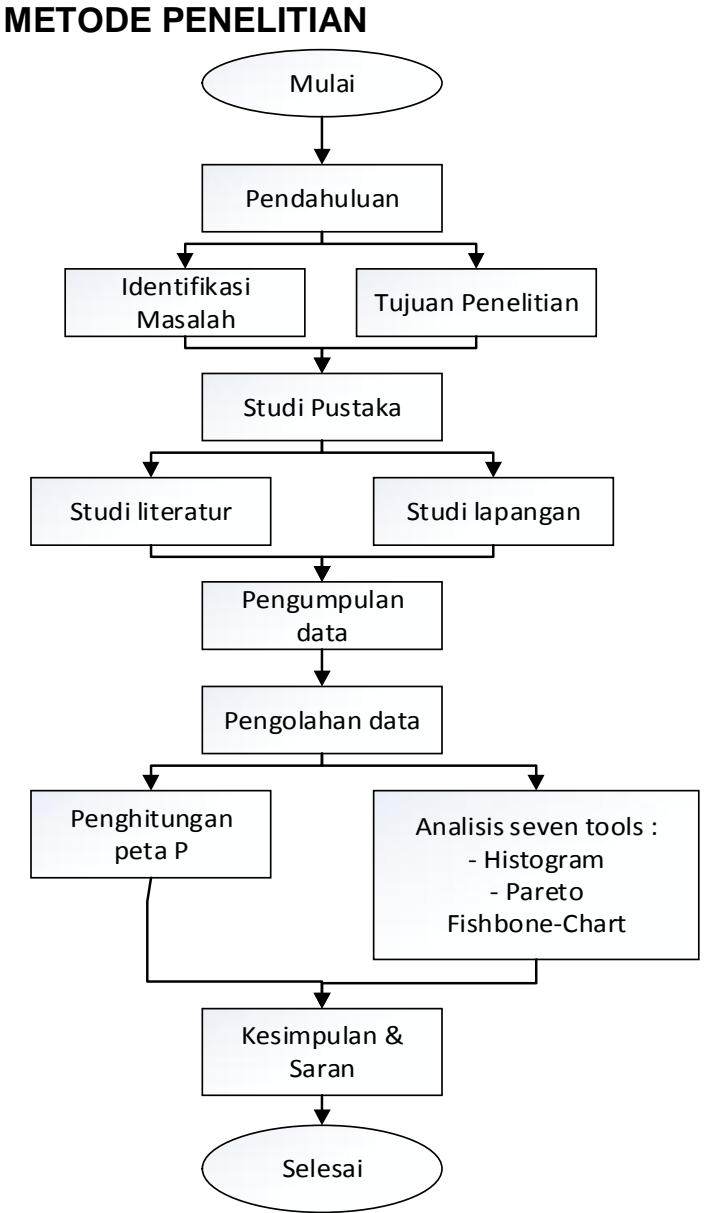

Gambar 1 Alur Penelitian

\section{HASIL DAN PEMBAHASAN}

1. Pengumpulan data

Berdasarkan perolehan data melalui wawancara diperoleh data kecacatan pada produksi roti basah manis pada PT. Candrabuana Surya Semesta, diantaranya adonan tidak mengembang dan pembakaran tidak sempurna. Berikut ini adalah perolehan data kecacatan roti basah manis :

Tabel 1 Data Produksi Roti Basah Manis

\begin{tabular}{|l|l|l|l|}
\hline Hari & $\begin{array}{c}\text { Jumlah } \\
\text { Produksi } \\
(\mathrm{n})\end{array}$ & $\begin{array}{c}\text { cacat } \\
\text { adonan } \\
\text { tidak } \\
\text { mengem- } \\
\text { bang }\end{array}$ & $\begin{array}{c}\text { cacat } \\
\text { pemba- } \\
\text { karan } \\
\text { tidak } \\
\text { sempurna }\end{array}$ \\
\hline 1 & 4.000 & 304 & 104 \\
\hline 2 & 4.700 & 309 & 151 \\
\hline 3 & 6.100 & 245 & 179 \\
\hline 4 & 5.900 & 314 & 196 \\
\hline 5 & 4.300 & 229 & 135 \\
\hline 6 & 6.500 & 248 & 170 \\
\hline 7 & 5.000 & 221 & 158 \\
\hline jumlah & 36.500 & 1.870 & 1.093 \\
\hline
\end{tabular}

Sumber data primer diperoleh 2019 
2. Pengolahan Data

2.1. Pengolahan data cacat dengan menggunakan peta $\mathrm{P}$

\begin{tabular}{|l|c|l|l|l|}
\hline Hari & $\begin{array}{c}\text { bagian } \\
\text { ditolak } \\
(\mathrm{Pi})\end{array}$ & $\mathrm{p}(\mathrm{CL})$ & $\mathrm{UCL}$ & $\mathrm{LCL}$ \\
\hline 1 & 0,102 & 0,081 & 0,094 & 0,068 \\
\hline 2 & 0,098 & 0,081 & 0,093 & 0,069 \\
\hline 3 & 0,070 & 0,081 & 0,092 & 0,071 \\
\hline 4 & 0,086 & 0,081 & 0,092 & 0,071 \\
\hline 5 & 0,085 & 0,081 & 0,094 & 0,069 \\
\hline 6 & 0,064 & 0,081 & 0,091 & 0,071 \\
\hline 7 & 0,076 & 0,081 & 0,093 & 0,070 \\
\hline jumlah & 0,081 & & & \\
\hline
\end{tabular}

2.2. Peta Kendali Produk Roti Basah Manis

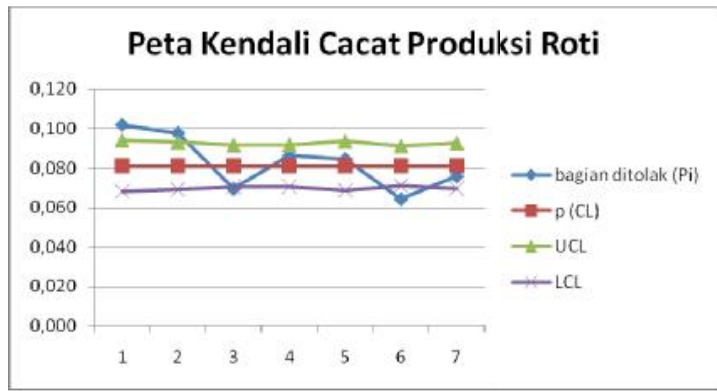

Gambar 2 Peta Kendali Cacat Produksi Roti Basah Manis

Berdasarkan peta kendali diatas produk cacat produksi roti basah masih ada yang keluar dari batas atas (UCL) maupun batas bawah (LCL), sehingga dapat diketahui bahwa produksi roti basah masih belum terkendali dan membutuhkan perbaikan.

\subsection{Histogram}

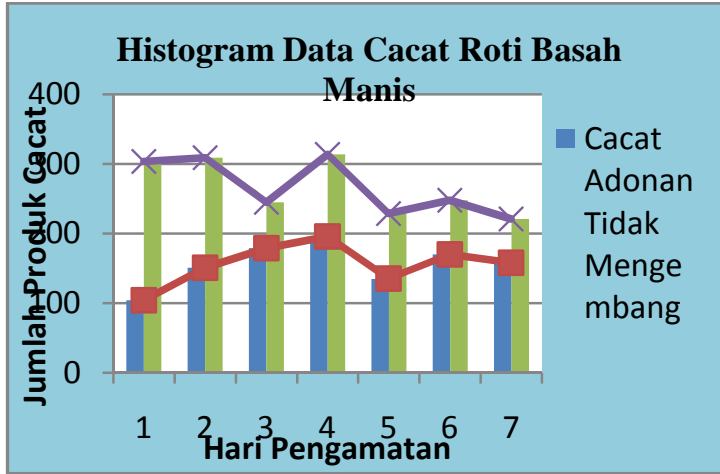

Gambar 3 Histogram Data cacat Roti basah manis

Berdasarkan data histogram diatas, dapat diketahui bahwa performansi dari nilai cacat dari masing-masing kecacatan masih cukup tinggi setiap harinya. Sehingga dibutuhkan evaluasi dan perbaikan dalam proses produksinya.

\subsection{Pareto Chart}

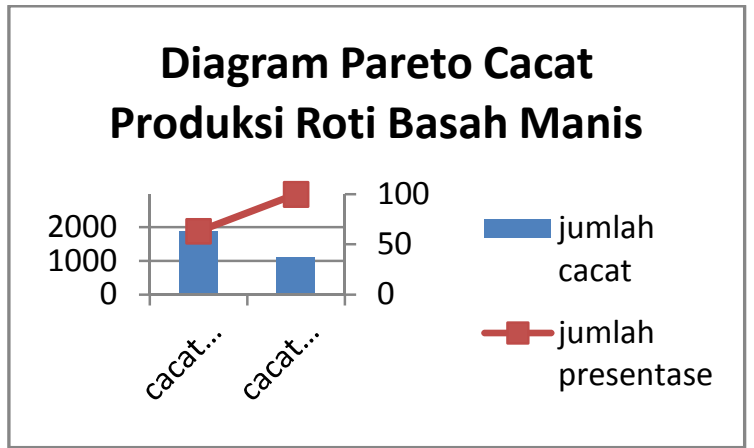

Gambar 4. Diagram pareto data cacat produksi roti basah manis

Dari gambar pareto diatas, cacat adonan tidak mengembang adalah jumlah cacat paling banyak. Hal ini dapat dijadikan acuan perusahaan dalam melakukan prioritas perbaikan dalam perusahaan,

\subsection{Fishbone Chart}

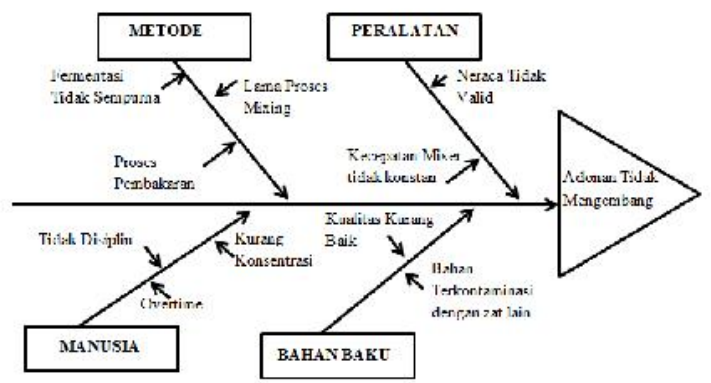

Diagram 5 Fishbone Chart data cacat adonan tidak mengembang

Berdasarkan diagram diatas dapat diketahui faktor-faktor yang menyebabkan adonan tidak mengembang adalah :

1) Faktor Metode

a) Fermentasi tidak sempurna

b) Proses pembakaran

c) Lama proses mixing

2) Faktor Peralatan

a) Neraca tidak valid

b) Kecepatan mixer tidak konstan.

3) Faktor Manusia

a) Tidak disiplin

b) Overtime

c) Kurang Konsentrasi

4) Faktor Material/Bahan Baku

a) Kualitas kurang baik. 
b) Bahan baku terkontaminasi dengan zat lain.

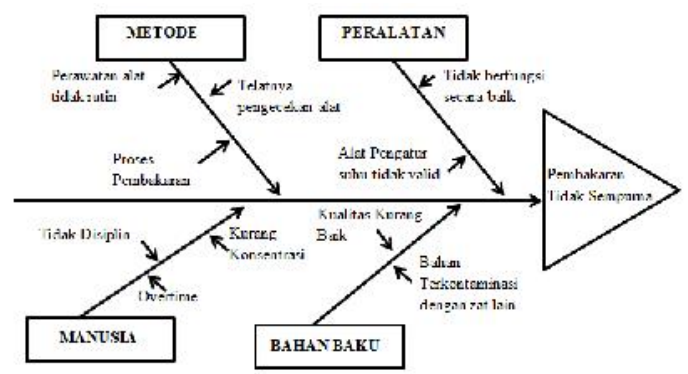

Diagram 6 Fishbone Chart data cacat pembakaran tidak sempurna

Berdasarkan diagram diatas dapat diketahui faktor-faktor yang menyebabkan pembakaran tidak sempurna adalah :

1. Faktor Metode
a. Telatnya pengecekan alat
b. Perawatan alat tidak rutin
c. Proses pembakaran

2. Faktor Peralatan
a. Alat pengatur suhu tidak valid
b. Alat tidak berfungsi dengan baik.

3. Faktor Manusia
a. Tidak disiplin
b. Overtime
c. Kurang Konsentrasi

4. Faktor Material/Bahan Baku

a. Kualitas kurang baik.

b. Bahan baku terkontaminasi dengan zat lain.

\section{SIMPULAN}

Dari hasil pengolahan dan analisis data dari proses produksi roti basah manis di PT. Candrabuana Surya Semesta yang telah dilakukan, dapat disimpulkan bahwa

1. secara umum proses produksi masih belum dalam batas kendali. Hasil 7 hari pengamatan dan perhitungan dengan menggunakan peta $\mathrm{P}$, terdapat 3 data yang keluar dari batas kontrol atas (UCL) dan batas kontrol bawah (LCL).

2. Pengolahan data menggunakan seven tools of quality menunjukkan :

i. analisis histogram memperlihatkan data masih mengalami persebaran cacat yang cukup tinggi. Kecacatan yang terdapat pada proses produksi roti basah manis yaitu adonan tidak mengembang dan pembakaran tidak sempurna.

ii. pengolahan data pareto dapat ditampilkan bahwa cacat adonan tidak sempurna menjadi prioritas pertama untuk dapat dilakukan perbaikan.

iii. analisis fishbone-chart, secara umum faktor-faktor penyebab kecacatan yaitu : metode, peralatan, manusia/karyawan, dan bahan baku.

\section{DAFTAR PUSTAKA}

Barry, Render \& Jay Haizer. 2001. Prinsipprinsip Manajemen Operasi : Operation Management. Jakarta : Salemba Empat.

Gasperz, Vincent. 2005. Total Quality Management. Jakarta : Gramedia Pustaka Utama

Haizer, Jay \& Barry Render. 2015. Manajemen Operasi Manajemen Keberlangsungan dan Rantai Pasokan. Jakarta : Salemba Empat.

Handoko, T. Hani. 1999. Dasar-dasar Manajemen Produksi dan Operasi. Yogyakarta : BPFE Yogyakarta.

Hidayat, Agung. 2017. Bisnis Roti dan Kue Indonesia Bertumbuh $10 \%$. https://industri.kontan.co.id/news/bisni s-roti-dan-kue-indonesia-bertumbuh10 diakses pada 15 Mei 2019.

Prawirosentono, Suyadi. 2009. Manajemen Operasi (Operation Management) : Analisis dan Studi Kasus. Jakarta : PT. Bumi Aksara.

Sulaeman. 2015. Analisa Pengendalian Kualitas untuk Mengurangi Produk Cacat Speedometer Mobil dengan Menggunakan Metode QCC di PT. INS. Jurnal PastiVolume VIII No. 1, 71-95.

Tjiptono, Fandy \& Anastasia Diana. 2003. Total Quality Management. Yogyakarta : Andi. 